\title{
Botulinum Toxin A: A Review of Potential Uses in Treatment of Female Urogenital and Pelvic Floor Disorders
}

\author{
Laurephile Desrosiers, DO, ${ }^{1,2}$ Leise R. Knoepp, MD, MPH ${ }^{1,2}$ \\ ${ }^{1}$ Department of Obstetrics and Gynecology, Division of Female Pelvic Medicine and Reconstructive Surgery, Ochsner Clinic Foundation, \\ New Orleans, LA ${ }^{2}$ The University of Queensland Faculty of Medicine, Ochsner Clinical School, New Orleans, LA
}

\begin{abstract}
Background: Botulinum toxin is an injectable neuromodulator that inhibits transmission between peripheral nerve endings and muscle fibers, resulting in muscle paralysis. Botulinum toxin type $A$ is the most common form of botulinum toxin used in clinical practice.

Methods: In this review, we examine the mechanism of action, formulations, common clinical use in the genital-urinary tract, and potential clinical use in pelvic floor disorders of botulinum toxin type $A$.

Results: Several aspects of botulinum toxin A make it a favorable therapeutic tool, including its accessibility, its longevity, and its impermanence and reversibility of resultant chemodenervation in a relatively short and safe manner. Although botulinum toxin $A$ has well-established efficacy in treating refractory overactive bladder and neurogenic detrusor overactivity, its use in pelvic floor disorders is still in its infancy.

Conclusion: The efficacy of botulinum toxin A for treating pelvic pain, voiding dysfunction, muscle pain and dysfunction, and certain colorectal-related pain issues shows promise but requires additional rigorous evaluation.
\end{abstract}

Keywords: Botulinum toxins-type A, pelvic floor disorders, pelvic pain, urogenital system

Address correspondence to Leise R. Knoepp, MD, MPH, Department of Obstetrics and Gynecology, Division of Female Pelvic Medicine and Reconstructive Surgery, Ochsner Baptist Hospital, 4429 Clara St., McFarland Bldg., Ste. 440, New Orleans, LA 70115. Tel: (504) 842-9618. Email: Iknoepp@ochsner.org

\section{INTRODUCTION}

Botulinum toxin is an injectable neuromodulator derived from neurotoxins produced by Clostridium botulinum, a gram-positive, rod-shaped anaerobic bacterium responsible for the production of the botulism-inducing neurotoxin. This neurotoxin inhibits transmission between peripheral nerve endings and muscle fibers, resulting in weakness or flaccid paralysis of skeletal muscle. The clinical potential of $C$ botulinum was recognized initially in 1897 when the toxin produced by the organism was identified as the etiologic agent of botulism. ${ }^{1,2}$ Since then, 7 serotypes of botulinum toxin (A, B, C1, D, E, F, and G), produced by different strains of the bacterium, have been identified. Although the pharmacologic properties of the serotypes differ, suggesting differences in clinical efficacy, only serotypes $A$ and $B$ are available for clinical use. Several aspects of botulinum toxin A make it a favorable therapeutic tool, such as injection longevity (effects last 3 to 4 months when injected into skeletal muscle and 6 to 9 months when injected into smooth muscle) and impermanence and reversibility (recovery of resultant chemodenervation after 3 to 6 months because of synaptic turnover). ${ }^{3,4}$ Botulinum toxin type $A$ is the most common form of botulinum toxin used in clinical practice ${ }^{5-7}$ and is the primary focus of this review in which we examine its mechanism of action, formulations, common clinical use in the genital-urinary tract, and potential clinical use in pelvic floor disorders.

\section{MECHANISM OF ACTION}

The clinical utility of botulinum toxin stems from its ability to prevent muscular contraction through inhibiting the release of acetylcholine from peripheral nerve cells into their neuromuscular junctions. In short, release of acetylcholine is suppressed sequentially as follows: toxin receptor binding and internalization, followed by cleaving and inhibition of acetylcholine. Botulinum toxins are peptides composed of one heavy chain and one light chain. After the heavy chain of the injected toxin binds to the terminal ends of a neuron, the peptide enters the cytoplasm through endocytosis. Once within the cytoplasm, the light chain cleaves components of soluble $\mathrm{N}$-ethylmaleimide-sensitive factor attachment protein receptor (SNARE), a complex of proteins necessary for the exocytosis of acetylcholine. The sites of cleavage within the SNARE protein complex differ among the serotypes; while botulinum toxin types $A, C 1$, and $E$ cleave synaptosome-associated protein of $25 \mathrm{kDa}$ (SNAP25), serotypes $B, D, F$, and $G$ cleave vesicle-associated membrane protein (VAMP), also known as synaptobrevin (Figure 1). ${ }^{8}$ As a result of cleavage, acetylcholine remains within the neuron where it is unable to bind to recep- 

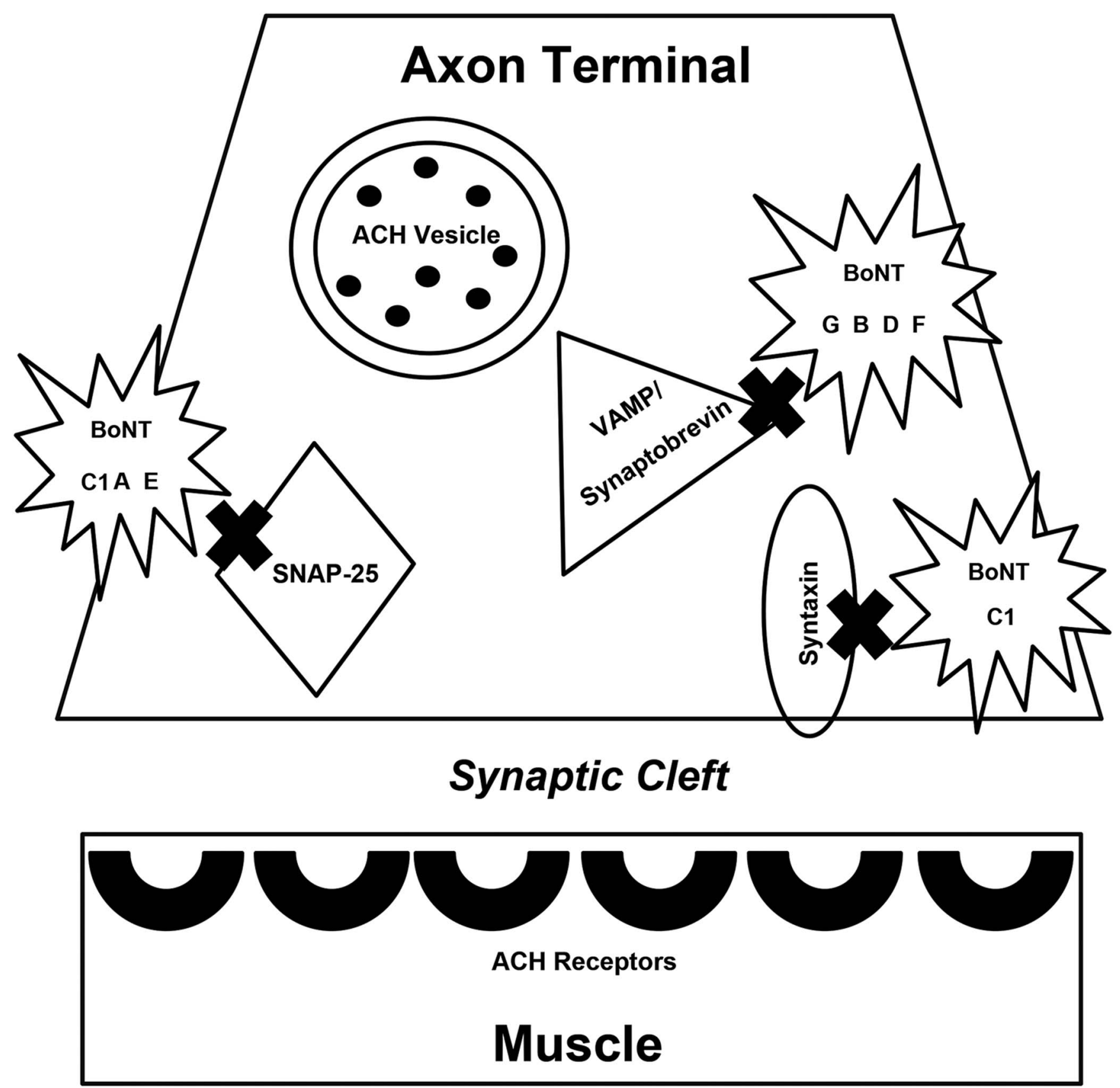

Figure 1. Mechanism of action of different botulinum toxin (BoNT) types. The acetylcholine (ACH) vesicle binds the soluble $\mathrm{N}$-ethylmaleimide-sensitive factor attachment protein receptor (SNARE) complex (synaptosome-associated protein of 25kDa [SNAP-25]), vesicle-associated membrane protein [VAMP]/synaptobrevin, syntaxin) to allow exocytosis of the neurotransmitter ACH from the axon into the synaptic cleft where it can bind end receptors on the muscle, allowing muscle contraction. Different types of BoNT affect different parts of the SNARE complex, preventing exocytosis of ACH, resulting in muscle paralysis. This diagram shows the specific sites affected by each BoNT type.

tors on muscle fibers and stimulate muscle contraction (chemodenervation).

The inhibitory effect of botulinum toxin is temporary; recovery of muscular function often becomes clinically evident approximately 3 to 6 months after treatment as the neuromuscular junction begins to recover. The development of new collateral nerve endings may be partially responsible for this recovery. However, these terminal buds appear to be transient, and recovery of the original nerve terminal eventually occurs, resulting in reversal of the toxin's effect. ${ }^{8-10}$

\section{FORMULATIONS}

As stated previously, 2 serotypes of botulinum toxin have been formulated for clinical use: type $A$ (the most common serotype used for cosmetic applications) and type B. Commercially available formulations of botulinum toxin type $A$ in 
Table. Clinical Applications of Botox in the Treatment of Urogenital and Pelvic Floor Disorders

\begin{tabular}{|c|c|c|c|}
\hline Disorder & Treatment, IU & Location & Level of Recommendation \\
\hline \multicolumn{4}{|l|}{ Urologic } \\
\hline Idiopathic detrusor overactivity & 100 & Bladder & A \\
\hline Neurogenic detrusor overactivity & 200 & Bladder & $A$ \\
\hline Dyssynergic sphincter deficiency & 200 & Bladder & $\mathrm{C}$ \\
\hline Interstitial cystitis/painful bladder syndrome & $100-200$ & Bladder & $\mathrm{C}$ \\
\hline \multicolumn{4}{|l|}{ Gynecologic } \\
\hline Pudendal neuralgia & $15-60$ & Muscle & $\mathrm{C}$ \\
\hline High tone pelvic floor dysfunction & $20-100$ & Muscle & $\mathrm{C}$ \\
\hline Vestibulodynia & $20-100$ & Perineum & B \\
\hline \multicolumn{4}{|l|}{ Colorectal } \\
\hline Anal fissure & $20-300$ & Internal anal sphincter & B \\
\hline Puborectalis syndrome (anismus) & $12-100$ & $\begin{array}{l}3 \text { and } 9 \text { o'clock by puborectalis } \\
\text { muscle }\end{array}$ & $B$ \\
\hline Hemorrhoids and healing & $20-100$ & Internal anal sphincter & B \\
\hline Anal pain & $20-200$ & $\begin{array}{l}\text { Muscle and/or internal anal } \\
\text { sphincter }\end{array}$ & B \\
\hline
\end{tabular}

Note: Levels of recommendation are (A) based on at least one randomized clinical trial as part of the scientific evidence and overall represents good and consistent scientific evidence; (B) methodologically correct, but nonrandomized clinical trials on the topic overall are based on limited and inconsistent scientific evidence; and (C) consensus and expert opinions or committee recommendations, but high-quality directly applicable clinical studies are lacking.

North America include onabotulinumtoxinA, abobotulinumtoxinA, and incobotulinumtoxinA. RimabotulinumtoxinB is the established name for botulinum toxin type B. ${ }^{11}$ Of the formulations of botulinum toxin type $A$ that are available in 2020 or in development, onabotulinumtoxinA has been studied most extensively.

\section{APPROVED USES FOR UROGENITAL DISORDERS}

Botulinum toxin is US Food and Drug Administration (FDA)-indicated for multiple purposes, but with regard to urogenital and pelvic floor disorders (Table), in 2020, it is only approved for (1) treatment of overactive bladder with symptoms of urinary urge incontinence, urgency, and frequency in adults who have an inadequate response to or are intolerant of an anticholinergic medication, and (2) treatment of urinary incontinence because of detrusor overactivity associated with a neurologic condition (eg, spinal cord injury, multiple sclerosis) in adults who have an inadequate response to or are intolerant of an anticholinergic medication. ${ }^{12}$ Botox (onabotulinumtoxinA) has been FDA approved for treatment of neurogenic detrusor overactivity since 2011 and for refractory overactive bladder symptoms since $2013,{ }^{13}$ increasing the likelihood of insurance coverage, and thus the affordability of and access to this treatment for pelvic floor indications. Additionally, studies have shown Botox to be cost effective relative to nonselective anticholinergics, advocating for consideration as a first-line treatment for overactive bladder. ${ }^{14}$

\section{Overactive Bladder}

Botox has been effective in treating refractory overactive bladder and is usually given at doses of 100 to 300 $\mathrm{IU}^{15-17}$ every 6 to 12 months, with most clinicians administer- ing 100-IU doses to minimize side effects. ${ }^{4}$ Compelling evidence from a 2011 meta-analysis noted significant reduction in urinary frequency and urge incontinence at 6 and 12 weeks compared with placebo treatment. ${ }^{18}$ Multiple studies have also shown that this treatment regimen has some duration, although time of efficacy after each injection has been variable. ${ }^{19,20}$ In initial trials, time to retreatment after injection of $100 \mathrm{IU}$ of injected onabotulinumtoxinA was 19 to 24 weeks, leading the manufacturer to recommend passage of at least 12 weeks between injections. ${ }^{12}$ Predictors of treatment success have been assessed, although also with inconsistent results. Female participants (especially $<65$ years old) with low overactive bladder symptom scores on preoperative questionnaires, subjects with wet overactive bladder, and subjects who stopped other treatments before undergoing Botox injection have all been found to have higher success rates with treatment. ${ }^{21-23}$

\section{Neurogenic Detrusor Overactivity}

Botox injections have also been useful in the treatment of neurogenic detrusor overactivity, while protecting the upper urinary tract and improving quality of life through decreasing overall urge incontinence episodes. ${ }^{24}$ In a large metaanalysis, subjects receiving treatment experienced a reduction in urinary urge incontinence episodes per week and maximum detrusor voiding pressure, while increasing maximum cystometric capacity. ${ }^{25}$ Although doses of 200 to $300 \mathrm{IU}$ have been studied, injection of $200 \mathrm{IU}$ has been found to have optimized efficacy while minimizing potential side effects. $^{26}$

Injection of Botox for urinary symptoms is generally through a rigid or flexible cystoscope, with the total dose divided and administered in 10 to 20 small injections into the 
detrusor muscle of the bladder. The specifics about injection technique, such as the optimal intravesical anatomic location and the number of injections, are still topics of debate, although limited studies have not demonstrated increased rates of urinary retention, frequency of urinary tract infections, or vesicoureteral reflux after trigonal injection. ${ }^{27,28} \mathrm{~A}$ European consensus report includes some discussion about the efficacy of suburothelial vs intradetrusor injections. ${ }^{29}$

Although Botox treatment is typically considered safe for use in the treatment of overactive bladder and neurogenic detrusor overactivity, the potential for adverse effects exists. Most significantly, high injection doses (300 to 1,000 IU) have (rarely) been associated with generalized weakness ${ }^{29}$ and life-threatening toxicity, similar to typical botulism, resulting in issuance of an FDA warning in 2009. ${ }^{13}$ More commonly, Botox injections for urinary issues can result in increased rates of urinary retention and increased frequency of urinary tract infections. ${ }^{12}$

\section{POTENTIAL USES FOR PELVIC FLOOR DISORDERS}

As of 2020, Botox is not FDA approved for the pelvic floor disorders discussed in this section; however, data show that the use of Botox in these areas is promising.

\section{Female Pelvic Pain}

Pelvic pain in women, which is a major cause of morbidity and disability for patients and results in significant costs to health services, is a complex and challenging dilemma. When the cause of pain can be defined, the majority of women experiencing acute pain can be effectively treated with medical and surgical interventions. However, in a subset of patients, diagnosing the cause of pain can be evasive, and these patients often have decreased success and dissatisfaction with treatment. As a further complication, chronic pelvic pain is not only influenced by multiple systems (neurologic, musculoskeletal, endocrine), but a growing body of evidence also shows a strong behavioral and psychological component. Given its potential analgesic effects, Botox may be a potential treatment modality for pelvic pain. These analgesic effects are likely attributable to secondary effects achieved from muscle paralysis, which leads to improved blood flow, decompression of nerve fibers by abnormally contracting muscle, and downregulation of nociceptive neurons.

Pudendal Neuralgia. Sacral roots S2 to S4 coalesce to form the pudendal nerve. Typically, the pudendal nerve courses underneath the piriformis muscle and between the sacrospinous and sacrotuberous ligaments at the level of the ischial spine. The pudendal nerve then travels through the Alcock canal between the obturator internus and levator ani muscles and divides into 3 branches: the dorsal nerve of the clitoris (or penis), the perineal nerve, and the inferior rectal nerve. The 2 most common areas of nerve entrapment occur at the level of the ischial spine and the Alcock canal. Damage to the pudendal nerve can result in unilateral or bilateral pelvic pain in females, involving the vulva, vagina, clitoris, or bladder. Pudendal nerve dysfunction because of entrapment or compression has been postulated to not only lead to chronic pain but also to negatively impact the afferent, efferent, and autonomic signals between pelvic organs that are essential for maintaining their proper functions. ${ }^{30}$
Levator Myalgia. Levator myalgia is a condition characterized by burning pain or tenesmus of the perineum or rectum. In a 2004 study by Jarvis et al, 12 patients with a minimum 2-year history of chronic pelvic pain and pelvic floor hypertonicity underwent injection of $40 \mathrm{IU}$ of botulinum toxin A into bilateral levator ani muscles. ${ }^{30}$ Visual analog scale (VAS) scores and muscle manometry showed improvement at 4 weeks, which was maintained at the 12-week assessment. Abbott et al conducted a double-blind randomized controlled trial in which women received pelvic floor injections of $80 \mathrm{IU}$ of Botox $(n=30)$ vs saline $(n=30) .{ }^{31}$ Significant improvement in VAS scores and muscle manometry was noted in the Botox recipients. Adelowo et al published a retrospective review of 31 subjects who received Botox injections of 100 to $300 \mathrm{IU}$ for myofascial pain. ${ }^{32}$ Primary outcomes were self-reported pain on muscle palpation and symptom improvement. The median pain noted with levator palpation was significantly lower at 6 weeks $(P<0.0001)$ postinjection and remained significantly decreased at 12 weeks $(P<0.0001)$. Within the cohort, $58 \%$ opted to have a repeat injection, with a median time to repeat injection of 4 months. Adverse side effects included de novo urinary retention (10.3\%), fecal incontinence (6.9\%), and constipation and/or rectal pain (10.3\%), all of which resolved spontaneously. In 2013, a prospective study by Nesbitt-Hawes et al assessed successive botulinum toxin $A$ injections in women with pelvic floor disorders. ${ }^{33}$ Thirty-seven patients received injections of $100 \mathrm{IU}$ of botulinum toxin $\mathrm{A}$ into the puborectalis and pubococcygeus muscles, with $30 \%$ receiving 2 or more injections. The VAS scores and vaginal pressure measured by manometry were evaluated at $0,4,12$, and 26 weeks. Both single and repeated injections demonstrated a statistically significant reduction in dyspareunia $(P=0.001)$ as measured by VAS scores, but vaginal pressure improvement was only noted in the multiple injection group $(P=0.02)$. No differences in dysmenorrhea or dyschezia rates were observed. In 2015, Morrissey et al selected subjects with chronic pelvic pain and high muscle tone pelvic floor dysfunction who had failed conventional therapy to receive Botox injections (maximum dose $300 \mathrm{IU}$ ) through electromyography guidance, allowing specific localization of spasticity in pelvic floor muscles. ${ }^{34}$ Posttreatment vaginal manometry demonstrated significant decreases in resting pressure and maximum contraction pressures $(P<0.05)$. Adverse effects after injections included constipation (28\%), stress urinary incontinence (4.8\%), and fecal incontinence (4.8\%).

Vulvodynia. Vulvodynia is characterized by burning pain in the vulvar area, persistent for at least 3 months, in the absence of other relevant dermatologic or neurologic findings. Vulvodynia negatively impacts quality of life, and various treatment modalities, including surgery and yttrium aluminum garnet (YAG) lasers, have been useful in reducing this type of pain. ${ }^{35,36}$ Postulated efficacy in this subset of patients with pelvic pain is based on the effect of Botox at the neuromuscular junction and within parasympathetic and sympathetic neural synapses. The first report of Botox used to treat vulvovaginal pain was in 1997, when Brin and Vapnek published their data on successful treatment of vaginismus with Botox. ${ }^{37}$ In 2000, after injection of Botox vs saline in a small population, Shafik and El-Sibai found superiority in pain control for the Botox group. ${ }^{38}$ In 2004, Gunter et al described successful management of refractory vulvodynia with a 
combination of surgery and Botox. ${ }^{39}$ Since that time, other studies have reported improvement in vulvodynia, ${ }^{40-45}$ while others have found no change in symptoms. ${ }^{46}$ In 2017 , Halder et al reported improved VAS scores after treatment with combined Botox and physical therapist-mediated myofascial release. ${ }^{47}$ Posttreatment complications included constipation $(8 \%)$, urinary retention $(2 \%)$, and urinary tract infections (4\%). In an effort to improve injection success, NesbittHawes et al developed a technique using 4-dimensional sonogram guidance to aid injection. ${ }^{48}$ Their findings have shown good feasibility while allowing accurate placement of the injection within the target muscle in women with pelvic floor muscle overactivity.

Interstitial Cystitis. Now more commonly termed bladder pain syndrome, interstitial cystitis is a type of chronic pain that affects the bladder and pelvic floor. Symptoms vary but often include persistent urinary urgency and frequency, dyspareunia, bladder base tenderness, and levator myalgia. Interstitial cystitis/bladder pain syndrome also has strong associations with depression and anxiety, irritable bowel syndrome, and fibromyalgia. Although the exact pathophysiology of interstitial cystitis/bladder pain syndrome is unknown, several theories exist; the most common faults disruption in the glycosaminoglycan of the basement membrane of the bladder that leads to greater infiltration of irritating substances. Generally, glomerulations, petechial hemorrhages, or other signs of inflammation can be seen on cystoscopy, but the identification of a Hunner ulceration has greater specificity for interstitial cystitis/bladder pain syndrome diagnosis and is usually associated with more severe symptoms. To date, 3 double-blind randomized controlled studies have evaluated the use of botulinum toxin $A$ in the treatment of interstitial cystitis/bladder pain syndrome. Kuo and Kuo compared 100 IU Botox vs saline, and the botulinum toxin A group showed a significantly greater reduction in VAS scores and global improvement response assessment at 3 months. ${ }^{49}$ Chuang and Kuo evaluated the use of intravesical instillation of a liposomal lipotoxin form of Botox in patients with interstitial cystitis/bladder pain syndrome. ${ }^{50}$ Significant improvement was noted at 4 weeks; however, no differences in endpoints were appreciated among the groups at 12 weeks. In 2018, Pinto et al also found a significant reduction in VAS scores in the subjects receiving botulinum toxin $A$ vs placebo. ${ }^{51}$ Studies by Rappaport et al and Jiang et al assessed hydrogel-based delivery systems and trigonal intravesical injections, respectively, and the studies demonstrated safety and at least shortterm efficacy with both techniques. ${ }^{52,53}$ In 2020, no consensus exists regarding the efficacy of treating interstitial cystitis/bladder pain syndrome with botulinum toxin A. However, studies suggest a trend toward improvement in symptoms. Well-designed studies are needed to further evaluate this trend, as well as to define ideal dosage, injection location, and alternate delivery systems.

Postoperative Pelvic Pain. Postoperative pelvic pain is complex in its presentation and treatment. Studies concerning the utility of Botox injections in treating this type of pain are limited, but Park and Paraiso reported successfully treating a patient presenting with de novo refractory dyspareunia after pelvic floor reconstructive surgery. ${ }^{45}$ More research is needed to fully define the role of Botox in the treatment of postoperative pelvic pain.
As the discussion in this section has demonstrated, the indications for Botox treatment are not entirely clear for patients experiencing different types of pelvic pain. However, treatment of such pain with Botox shows promise in conditions such as chronic pelvic floor muscle spasm (primary or etiology) and interstitial cystitis/bladder pain syndrome. Botox should be considered for patients with refractory cases who have received proper counseling about the use of Botox in treating their condition. The clinician should proceed with caution before considering using Botox to treat a patient with pelvic pain, as Botox is only FDA approved for pain related to cervical dystonia. When treating different types of pelvic pain with botulinum toxin $A$, patients should be closely monitored within the bounds of ethical research standards.

\section{Urethral Sphincter Dyssynergia/Detrusor Sphincter Dyssynergia}

Evidence suggesting decreased postvoid residual, maximum urethral closure pressure, and maximum voiding detrusor pressure after treatment with Botox-while still protecting the upper urinary tract-indicates that patients with detrusor sphincter dyssynergia may benefit from treatment with botulinum toxin A. Gallien et al published one of the largest trials evaluating the effectiveness and safety of Botox in 86 patients, 58 of whom were women, with detrusor sphincter dyssynergia secondary to multiple sclerosis. ${ }^{54}$ Subjects were randomized to intrasphincteric injection of Botox vs placebo. No significant difference in postvoid residual between the 2 groups was found. However, compared to placebo, Botox significantly increased voiding volume $(P=0.02)$ and reduced premicturition $(P=0.02)$ and maximal detrusor pressures $(P=0.02)$. Overall, female-specific data are lacking because many studies included either male-only or combined male/female populations, and additional studies are needed to fully understand the efficacy of botulinum toxin $A$ in treating detrusor sphincter dyssynergia in female patients.

\section{Colorectal Conditions That May Affect Pelvic Floor Symptoms}

Hemorrhoids. Treatment of hemorrhoids, especially with traditional hemorrhoidectomy, can cause significant postoperative pain. As postoperative pain for these cases can often be refractory to standard treatment options, development of new methods for pain control is paramount. In 2003, Davies et al reported decreased VAS scores in subjects who received internal anal sphincter injections of botulinum toxin A status post Milligan-Morgan hemorrhoidectomy compared with those who received placebo. ${ }^{55}$ Notably, no difference in narcotic use was seen between groups, and no anal incontinence or other complications were reported for the treatment group. Similarly, a study by Patti et al in 2005 showed improved wound healing after hemorrhoidectomy for thirdand fourth-degree piles in patients who received intrasphincteric botulinum toxin injection. ${ }^{56}$ Anorectal manometry was also evaluated preoperatively and postoperatively at intervals, with significant postoperative improvement noted in mean rectal pressure and decreased wound healing time in the Botox treatment group. Anal incontinence was reported for 9 patients, although cases were almost evenly distributed between Botox $(n=4)$ vs placebo $(n=5)$ recipients. A 2008 


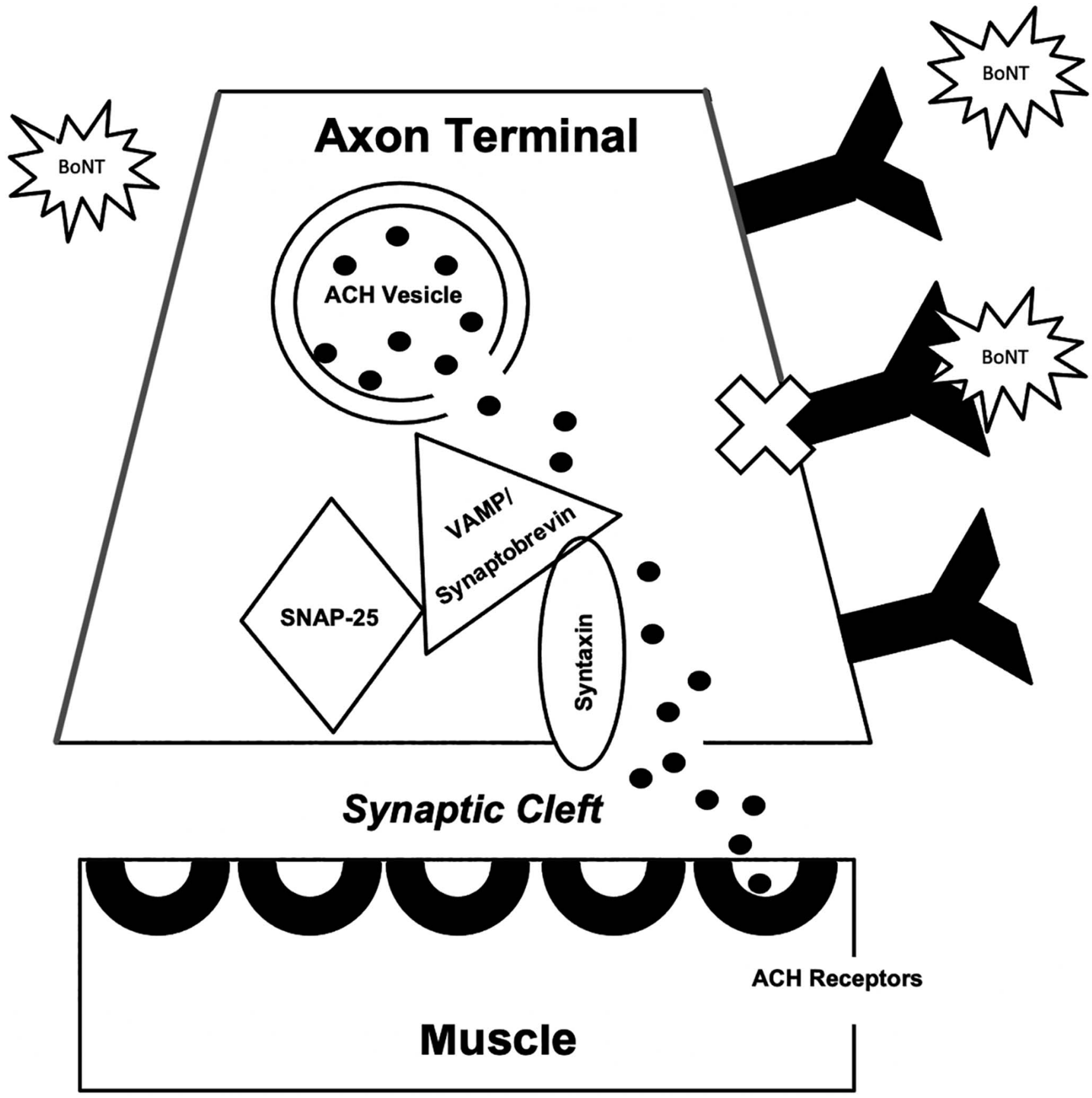

Figure 2. Mechanism of action of botulinum toxin (BoNT) immunogenicity. After repeated doses of BoNT, antibodies to BoNT may form. When BoNT binds to an antibody, it cannot enter the axon to block formation of the soluble N-ethylmaleimidesensitive factor attachment protein receptor (SNARE) complex (synaptosome-associated protein of 25kDa [SNAP-25], vesicleassociated membrane protein [VAMP]/synaptobrevin, syntaxin). Therefore, the SNARE complex forms, allowing exocytosis of the neurotransmitter acetylcholine $(\mathrm{ACH})$ from the axon into the synaptic cleft where it can bind end receptors on the muscle, allowing muscle contraction. Thus, efficacy of BoNT is decreased with antibody formation.

study by Patti et al assessed the utility of Botox injections for pain relief in the setting of thrombosed external hemorrhoids. ${ }^{57}$ Patients who refused surgical intervention were randomized to receive Botox vs placebo injection. Anorectal manometry was performed before the procedure and 5 days posttreatment. Anal resting pressure, pain, and time to return to work or normal activity were all decreased in the Botox group, while the placebo group had increased analgesic consumption. No patients in either group reported anal incontinence.

Anal Fissures. An anal fissure is a tear in the lining of the distal anal canal caudal to the dentate line that most commonly occurs along the posterior midline. The incidence is comparable in both sexes and affects people of varying 
ages. Clinical symptoms include anal pain during and after defecation, often accompanied by bright red rectal bleeding, and pruritus ani. Acute fissures typically have sharply demarcated fresh mucosal edges and may have granulation tissue along their bases. Chronic fissures typically have rolled edges, characteristically exposing the horizontal fibers of the internal anal sphincter muscle at their bases, and are often accompanied by external skin tags, hypertrophied anal papillae, elevated resting anal pressures, and, rarely, anal stenosis.

Studies assessing botulinum toxin A for treating anal fissures are limited. As early as 1998, Maria et al published a comparison of Botox and saline for the treatment of chronic anal fissures in the New England Journal of Medicine. ${ }^{58}$ The Botox group demonstrated higher fissure healing rates $(73 \%$ vs $13 \%)$, with only one subject experiencing transient incontinence of flatus. Botulinum toxin $A$ injection has also been compared with topical glyceryl trinitrate $0.2 \%$ for the treatment of patients with chronic anal fissures. ${ }^{59}$ Healing rates were significantly higher (96\% vs $60 \%)$, and resting anal pressures were decreased ( $29 \%$ vs $14 \%$ ) in the botulinum toxin A group vs the glyceryl trinitrate group. No side effects were noted in the Botox group, while $20 \%$ of the glyceryl trinitrate group complained of headaches. While surgical intervention for anal fissures, particularly with lateral internal sphincterotomy, is considered the therapeutic gold standard, multiple reports have compared lateral internal sphincterotomy to Botox treatment. Although Botox is inferior to lateral internal sphincterotomy when given alone, studies have shown Botox to be less invasive and repeatable and to have a decreased risk of long-term fecal or flatal incontinence compared with lateral internal sphincterotomy. ${ }^{60,61}$ of note, a study from 2015 showed that treatment with topical diltiazem combined with Botox injection had similar success rates to partial lateral internal sphincterotomy, and the botulinum toxin $A+$ topical diltiazem group had lower rates of fecal incontinence. ${ }^{62}$ In subjects with chronic anal fissures however, the healing rate was significantly higher in the partial lateral internal sphincterotomy group.

\section{CHALLENGES}

Despite demonstrating much utility in treating pelvic floor disorders, especially with regard to evolving therapies, the use of botulinum toxin $A$ is not without challenges. Researchers continue to investigate ideal dosing, injection placement, and administration technique reproducibility, all contributing to the likelihood that recipients will have successful outcomes while minimizing side effects.

Patients who receive multiple doses can potentially develop immunogenicity to Botox (Figure 2). As Botox is often given repeatedly because of its temporary effect, antibodies may develop, resulting in decreased efficacy over time. The 2 types of antibodies are neutralizing antibodies that bind primarily to the heavy chain of the core neurotoxin and nonneutralizing antibodies that bind to either accessory proteins of the toxin complex or the core neurotoxin in a way that has no effect on biologic effect of the toxin. ${ }^{63,64}$ Although immunogenicity does not signify conclusive formation of neutralizing antibodies, this type of antibody has been specifically associated with a secondary nonresponse or loss of response after a period of successful therapy. ${ }^{65}$ Laboratory tests (mouse diaphragm assay and mouse pro- tection assay) and clinical tests (sternocleidomastoid test, extensor digitorum brevis test, and frowning test) have been developed to detect the presence of Botox antibodies, but not all tests have good sensitivity and specificity.

If ascertainable, treatment of immunogenicity with specific immunoglobulins, immunosuppressants, or plasmapheresis would be ideal, although implementation of each is not without risks and logistic considerations. Prevention of immunogenicity remains the ultimate goal. Minimizing modifiable risk factors (history of shorter dosing intervals, increasing the number of booster doses, and higher doses of Botox per treatment), while acknowledging fixed genetic predisposition, could help reduce the certainty and impact of antigen formation. ${ }^{66}$ Injecting the smallest effective dose of Botox and waiting the longest possible time interval between treatments may decrease the potential for immunogenicity. ${ }^{67}$ Refractory cases may warrant revisiting other standard treatment modalities for the specific pelvic floor condition being treated.

\section{CONCLUSION}

Although botulinum toxin A has well-confirmed efficacy in treating certain urogenital conditions, such as refractory overactive bladder and neurogenic detrusor overactivity, use of Botox to treat different types of pelvic pain, muscle dysfunction, and certain colorectal-related pain issues is promising. Research is needed to provide justification to broaden FDA-approved indications for Botox in treating such conditions and thereby facilitate access to robust, affordable treatment options for patients with these ailments.

\section{ACKNOWLEDGMENTS}

The authors have no financial or proprietary interest in the subject matter of this article.

\section{REFERENCES}

1. DasGupta BR. Structures of botulinum neurotoxin, its functional domains, and perspectives on the crystalline type $A$ toxin. In: Jankovic J, Hallet M, eds. Therapy with Botulinum Toxin. New York, NY: Marcel Dekker;1994:15.

2. Schantz EJ, Johnson EA. Botulinum toxin: the story of its development for the treatment of human disease. Perspect Biol Med. 1997 Spring;40(3):317-327. doi: 10.1353/pbm.1997.0032.

3. Dykstra DD, Sidi AA. Treatment of detrusor-sphincter dyssynergia with botulinum A toxin: a double-blind study. Arch Phys Med Rehabil. 1990;71(1):24-26.

4. Sahai A, Dowson C, Khan MS, Dasgupta P; GKT Botulinum Study Group. Repeated injections of botulinum toxin-A for idiopathic detrusor overactivity. Urology. 2010 Mar;75(3):552-558. doi: 10.1016/j.urology.2009.05.097.

5. Burke GS. Notes on Bacillus botulinus. J Bacteriol. 1919 Sep;4(5):555-570.1. doi: 10.1128/JB.4.5.555-570.1.1919.

6. Aoki KR, Guyer B. Botulinum toxin type A and other botulinum toxin serotypes: a comparative review of biochemical and pharmacological actions. Eur J Neurol. 2001 Nov;8 Suppl 5:21-29. doi: 10.1046/j.1468-1331.2001.00035.x.

7. Dolly JO, Lisk G, Foran PG, et al. Insights into the extended duration of neuroparalysis by botulinum neurotoxin $A$ relative to the other shorter-acting serotypes: differences between motor nerve terminals and cultured neurons. In: Brin MF, Jankovic J, Hallett M, eds. Scientific and Therapeutic Aspects of Botulinum Toxin. Philadelphia, PA: Lippincott Williams \& Wilkins; 2002:91. 
8. Giordano CN, Matarasso SL, Ozog DM. Injectable and topical neurotoxins in dermatology: basic science, anatomy, and therapeutic agents. J Am Acad Dermatol. 2017 Jun;76(6):1013-1024. doi: 10.1016/j.jaad.2016.11.022.

9. Meunier FA, Schiavo G, Molgó J. Botulinum neurotoxins: from paralysis to recovery of functional neuromuscular transmission. J Physiol Paris. 2002 Jan-Mar;96(1-2):105-113. doi: 10.1016/s0928-4257(01)00086-9.

10. Dressler D, Beneck R. Pharmacology of therapeutic botulinum toxin preparations. Disabil Rehab. $2007 \mathrm{Dec}$ 15;29(23):1761-1768. doi: 10.1080/09638280701568296.

11. Drugs@FDA: FDA-approved drugs. U.S. Food and Drug Administration. www.accessdata.fda.gov/scripts/cder/ drugsatfda/index.cfm?fuseaction $=$ Search.Label_ ApprovalHistory\#apphist. Accessed October 6, 2020.

12. Highlights of prescribing information. Botox (onabotulinumtoxinA). U.S. Food and Drug Administration. www.accessdata.fda.gov/drugsatfda_docs/label/2020/ 103000s5317lbl.pdf. Accessed October 6, 2020.

13. Botox (onabotulinumtoxinA). Drugs@FDA: FDA-approved drugs. U.S. Food and Drug Administration. www.accessdata. fda.gov/scripts/cder/daf/index.cfm?event=overview.process\& ApplNo=103000. Accessed October 6, 2020.

14. Shepherd JP, Carter-Brooks CM, Chermanksy C. A cost-effectiveness analysis of onabotulinumtoxin $A$ as first-line treatment for overactive bladder. Int Urogynecol J. 2018 Aug;29(8):1213-1219. doi: 10.1007/s00192-018-3653-z.

15. Brubaker L, Richter HE, Visco A, et al. Refractory idiopathic urge urinary incontinence and botulinum A injection. J Urol. 2008 Jul;180(1):217-222. doi: 10.1016/j.juro.2008.03.028.

16. Flynn MK, Amundsen CL, Perevich M, Liu F, Webster GD. Outcome of a randomized, double-blind, placebo controlled trial of botulinum A toxin for refractory overactive bladder. $J$ Urol. 2009 Jun;181(6):2608-2615. doi: 10.1016/j.juro.2009.01.117.

17. Sahai A, Khan MS, Dasgupta P. Efficacy of botulinum toxin-A for treating idiopathic detrusor overactivity: results from a single center, randomized, double-blind, placebo controlled trial. J Urol. 2007 Jun;177(6):2231-2236. doi: 10.1016/j.juro.2007.01.130.

18. Duthie JB, Vincent M, Herbison GP, Wilson DI, Wilson D. Botulinum toxin injections for adults with overactive bladder syndrome. Cochrane Database Syst Rev. 2011 Dec 7;(12):CD005493. doi: 10.1002/14651858.CD005493.pub3.

19. Owen RK, Abrams KR, Mayne C, Slack M, Tincello DG. Comparison of the effectiveness of repeated injections of onabotulinum toxin A for refractory idiopathic detrusor overactivity: analysis of an open label extension of a randomized trial (the RELAX study). Neurourol Urodyn. 2017 Apr;36(4):1201-1207. doi: 10.1002/nau.23095.

20. Chohan N, Hilton P, Brown K, Dixon L. Efficacy and duration of response to botulinum neurotoxin $A$ (onabotulinum $A$ ) as a treatment for detrusor overactivity in women. Int Urogynecol $\mathrm{J}$. 2015 Nov;26(11):1605-1612. doi: 10.1007/s00192-015-2751-4.

21. Hsiao SM, Lin HH, Kuo HC. Factors associated with therapeutic efficacy of intravesical onabotulinumtoxinA injection for overactive bladder syndrome. PLoS One. 2016 Jan 29;11(1):e0147137. doi: 10.1371/journal.pone.0147137.

22. Drake MJ, Nitti VW, Ginsberg DA, et al. Comparative assessment of the efficacy of onabotulinumtoxinA and oral therapies (anticholinergics and mirabegron) for overactive bladder: a systematic review and network meta-analysis. $B J U$ Int. 2017 Nov;120(5):611-622. doi: 10.1111/bju.13945.

23. Komesu YM, Amundsen CL, Richter HE, et al.; Eunice Kennedy Shriver National Institute of Child Health and Human
Development Pelvic Floor Disorders Network. Refractory urgency urinary incontinence treatment in women: impact of age on outcomes and complications. Am J Obstet Gynecol. 2018 Jan;218(1):111.e1-111.e9. doi: 10.1016/j.ajog.2017.10.006.

24. Weckx F, Tutolo M, De Ridder D, Van der Aa F. The role of botulinum toxin $A$ in treating neurogenic bladder. Trans/ Androl Urol. 2016 Feb;5(1):63-71.

25. Cheng T, Shuang WB, Jia DD. Efficacy and safety of onabotulinumtoxinA in patients with neurogenic detrusor overactivity: a systematic review and meta-analysis of randomized controlled trials. PloS One. $2016 \mathrm{Jul}$ 27;11(7):e0159307. doi: 10.1371/journal.pone.0159307.

26. Cruz F, Herschorn S, Aliotta $P$, et al. Efficacy and safety of onabotulinumtoxinA in patients with urinary incontinence due to neurogenic detrusor overactivity: a randomised, double-blind, placebo-controlled trial. Eur Urol. 2011 Oct;60(4):742-750. doi: 10.1016/j.eururo.2011.07.002.

27. Karsenty G, Elzayat E, Delapparent T, St-Denis B, Lemieux MC, Corcos J. Botulinum toxin type $A$ injections into the trigone to treat idiopathic overactive bladder do not induce vesicoureteral reflux. J Urol. 2007 Mar;177(3):1011-1014. doi: 10.1016/j.juro.2006.10.047.

28. Emami M, Shadpour $P$, Kashi AH, Choopani M, Zeighami M. Abobotulinum - a toxin injection in patients with refractory idiopathic detrusor overactivity: injections in detrusor, trigone and bladder neck or prostatic urethra, versus detrusor-only injections. Int Braz J Urol. 2017 Nov-Dec;43(6):1122-1128.

29. Apostolidis A, Dasgupta P, Denys P, et al; European Consensus Panel. Recommendations on the use of botulinum toxin in the treatment of lower urinary tract disorders and pelvic floor dysfunctions: a European consensus report. Eur Urol. 2009 Jan;55(1):100-119. doi: 10.1016/j.eururo.2008.09.009.

30. Jarvis SK, Abbott JA, Lenart MB, Steensma A, Vancaillie TG. Pilot study of botulinum toxin type $A$ in the treatment of chronic pelvic pain associated with spasm of the levator ani muscles. Aust N Z J Obstet Gynaecol. 2004 Feb;44(1):46-50. doi: 10.1111/j.1479-828X.2004.00163.x.

31. Abbott JA, Jarvis SK, Lyons SD, Thomson A, Vancaille TG. Botulinum toxin type $A$ for chronic pain and pelvic floor spasm in women: a randomized controlled trial. Obstet Gynecol. 2006 Oct;108(4):915-923. doi: 10.1097/01.AOG.0000237100.29870.cc.

32. Adelowo A, Hacker MR, Shapiro A, Modest AM, Elkadry E. Botulinum toxin type $A$ (BOTOX) for refractory myofascial pelvic pain. Female Pelvic Med Reconstr Surg. 2013 Sep-Oct;19(5):288-292. doi: 10.1097/SPV.0b013e3182989fd8.

33. Nesbitt-Hawes EM, Won H, Jarvis SK, Lyons SD, Vancaillie TG, Abbott JA. Improvement in pelvic pain with botulinum toxin type A-single vs. repeat injections. Toxicon. $2013 \mathrm{Mar}$ 1;63:83-87. doi: 10.1016/j.toxicon.2012.11.018.

34. Morrissey D, El-Khawand D, Ginzburg N, Wehbe S, O'Hare P, Whitmore K. Botulinum toxin A injections into pelvic floor muscles under electromyographic guidance for women with refractory high-tone pelvic floor dysfunction: a 6-month prospective pilot study. Female Pelvic Med Reconstr Surg. 2015 Sep-Oct;21(5):277-282. doi: 10.1097/SPV.0000000000000177.

35. Murina F, Karram M, Salvatore $S$, Felice R. Fractional $\mathrm{CO}_{2}$ laser treatment of the vestibule for patients with vestibulodynia and genitourinary syndrome of menopause: a pilot study. J Sex Med. 2016 Dec;13(12):1915-1917. doi: 10.1016/j.jsxm.2016.10.006.

36. Wu C, Goldstein A, Klebanoff JS, Moawad GN. Surgical management of neuroproliferative-associated vestibulodynia: a tutorial on vestibulectomy with vaginal advancement flap. 
Am J Obstet Gynecol. 2019 Nov;221(5):525.e1-525.e2. doi: 10.1016/j.ajog.2019.08.009.

37. Brin MF, Vapnek JM. Treatment of vaginismus with botulinum toxin injections. Lancet. 1997 Jan 25;349(9047):252-253. doi: 10.1016/S0140-6736(05)64862-3.

38. Shafik A, El-Sibai O. Vaginismus: results of treatment with botulin toxin. J Obstet Gynaecol. 2000 May;20(3):300-302. doi: 10.1080/01443610050009674.

39. Gunter J, Brewer A, Tawfik O. Botulinum toxin A for vulvodynia: a case report. J Pain. 2004 May;5(4):238-240. doi: 10.1016/j.jpain.2004.02.575.

40. Dykstra DD, Presthus J. Botuliniun toxin type A for the treatment of provoked vestibulodynia: an open-label, pilot study. J Reprod Med. 2006 Jun;51(6):467-470.

41. Yoon $\mathrm{H}$, Chung WS, Shim BS. Botulinum toxin A for the management of vulvodynia. Int J Impot Res. 2007 Jan-Feb;19(1):84-87. doi: 10.1038/sj.ijir.3901487.

42. Pelletier F, Parratte B, Penz S, Moreno JP, Aubin F, Humbert P. Efficacy of high doses of botulinum toxin $A$ for treating provoked vestibulodynia. Br J Dermatol. 2011 Mar;164(3):617-622. doi: 10.1111/j.1365-2133.2011.10235.x.

43. Tieu KD, MacGregor JL. Successful treatment of vulvodynia with botulinum toxin A. Arch Dermatol. 2011 Feb;147(2):251-252. doi: 10.1001/archdermatol.2010.443.

44. Jarrell J, Esfahani MN, Arendt-Nielsen L. Expansion of cutaneous allodynia in women with chronic pelvic pain due to visceral disease. Paper presented at: Pain in Europe, Congress of the European Federation of IASP Chapters (EFIC); October 9-12, 2013; Florence, Italy.

45. Park AJ, Paraiso MFR. Successful use of botulinum toxin type a in the treatment of refractory postoperative dyspareunia. Obstet Gynecol. 2009 Aug;114(2 Pt 2):484-487. doi: 10.1097/AOG.0b013e3181998ce1.

46. Petersen CD, Giraldi A, Lundvall L, Kristensen E. Botulinium toxin type A-a novel treatment for provoked vestibulodynia? Results from a randomized, placebo controlled double blinded study. J Sex Med. 2009 Sep;6(9):2523-2537. doi: 10.1111/j.1743-6109.2009.01378.x.

47. Halder GE, Scott L, Wyman A, et al. Botox combined with myofascial release physical therapy as a treatment for myofascial pelvic pain. Investig Clin Urol. 2017 Mar;58(2):134-139. doi: 10.4111/icu.2017.58.2.134.

48. Nesbitt-Hawes EM, Dietz HP, Abbott JA. Four-dimensional ultrasound guidance for pelvic floor botulinum toxin-A injection in chronic pelvic pain: a novel technique. Ultrasound Obstet Gynecol. 2018 Mar;51(3):396-400. doi: 10.1002/uog. 17537.

49. Kuo YC, Kuo HC. Adverse events of intravesical onabotulinumtoxina injection between patients with overactive bladder and interstitial cystitis-different mechanisms of action of Botox on bladder dysfunction? Toxins (Basel). 2016 Mar 16;8(3):75. doi: 10.3390/toxins8030075.

50. Chuang YC, Kuo HC. A prospective, multicenter, double-blind, randomized trial of bladder instillation of liposome formulation onabotulinumtoxinA for interstitial cystitis/bladder pain syndrome. J Urol. 2017 Aug;198(2):376-382. doi: 10.1016/j.juro.2017.02.021.

51. Pinto RA, Costa D, Morgado A, et al. Intratrigonal onabotulinumtoxinA improves bladder symptoms and quality of like in bladder pain syndrome/interstitial cystitis patients: a pilot, single center, randomized, double-blinded, placebo-controlled trial. J Urol. 2018 Apr;199(4):998-1003. doi: 10.1016/j.juro.2017.10.018.
52. Rappaport YH, Zisman A, Jeshurun-Gutshat M, et al. Safety and feasibility of intravesical instillation of botulinum toxin- $A$ in hydrogel-based slow-release delivery system in interstitial cystis/bladder pain syndrome patients: a pilot study. Urology. 2018 Apr;114:60-65. doi: 10.1016/j.urology.2017.12.028.

53. Jiang $\mathrm{YH}$, Jhang JF, Lee CL, Kuo HC. Comparative study of efficacy and safety between bladder body and trigonal intravesical onabotulinumtoxina injection in the treatment of interstitial cystitis refractory to conventional treatment-a prospective, randomized, clinical trial. Neurourol Urdoyn. 2018 Apr;37(4):1467-1473. doi: 10.1002/nau.23475.

54. Gallien P, Reymann JM, Amarenco G, Nicolas B, de Sèze M, Bellissant E. Placebo controlled, randomised, double blind study of the effects of botulinum A toxin on detrusor sphincter dyssynergia in multiple sclerosis patients. J Neurol Neurosurg Psychiatry. 2005 Dec;76(12):1670-1676. doi: 10.1136/jnnp.2004.045765.

55. Davies J, Duffy D, Boyt N, Aghahoseini A, Alexander D, Leveson S. Botulinum toxin (Botox) reduces pain after hemorrhoidectomy: results of a double-blind, randomized study. Dis Colon Rectum. 2003 Aug;46(8):1097-1102. doi: 10.1007/s10350-004-7286-6.

56. Patti R, Almasio PL, Muggeo VM, et al. Improvement of wound healing after hemorrhoidectomy: a double-blind, randomized study of botulinum toxin injection. Dis Colon Rectum. 2005 Dec;48(12):2173-2179. doi: 10.1007/s10350-005-0179-5.

57. Patti R, Arcara M, Bonventre $S$, et al. Randomized clinical trial of botulinum toxin injection for pain relief in patients with thrombosed external haemorrhoids. Br J Surgery. 2008 Nov;95(11):1339-1343. doi: 10.1002/bjs.6236.

58. Maria G, Cassetta E, Gui D, Brisinda G, Bentivoglio AR, Albanese A. A comparison of botulinum toxin and saline for the treatment of chronic anal fissure. N Engl J Med. 1998 Jan 22;338(4):217-220. doi: 10.1056/NEJM199801223380402.

59. Brisinda G, Maria G, Bentivoglio AR, Cassetta E, Gui D, Albanese A. A comparison of injections of botulinum toxin and topical nitroglycerin ointment for the treatment of chronic anal fissure. N Engl J Med. 1999 Jul 8;341(2):65-69. doi: 10.1056/NEJM199907083410201.

60. Yiannakopoulou E. Botulinum toxin and anal fissure: efficacy and safety systematic review. Int J Colorectal Dis. 2012 Jan;27(1):1-9. doi: 10.1007/s00384-011-1286-5.

61. Valizadeh N, Jalaly NY, Hassanzadeh M, et al. Botulinum toxin injection versus lateral internal sphincterotomy for the treatment of chronic anal fissure: randomized prospective controlled trial. Langenbecks Arch Surg. 2012 Oct;397(7):1093-1098. doi: 10.1007/s00423-012-0948-2.

62. Gandomkar H, Zeinoddini A, Heidari R, Amoli HA. Partial lateral internal sphincterotomy versus combined botulinum toxin $A$ injection and topical diltiazem in the treatment of chronic anal fissure: a randomized clinical trial. Dis Colon Rectum. 2015 Feb;58(2):228-234. doi: 10.1097/DCR.0000000000000307.

63. Goeschel H, Wohlfahrt K, Frevert J, Dengler R, Bigalke H. Botulinum A toxin: neutralizing and nonneutralizing antibodies - therapeutic consequences. Exp Neurol. 1997 Sep;147(1):96-102. doi: 10.1006/exnr.1997.6580.

64. Borodic G. Botulinum toxin, immunologic considerations with long-term, repeated use, with emphasis on cosmetic applications. Facial Plast Surg Clin North Am. 2007 Feb;15(1):11-16, v. doi: 10.1016/j.fsc.2006.10.001.

65. Slatkowski RM, Tyutyunikov A, Biglan AW, et al. Serum antibody production to botulinum A toxin. Ophthalmology. 1993 Dec;100(12):1861-1866. doi: 10.1016/s0161-6420(93)31384-9. 
66. Dressler D. Clinical presentation and management of antibody-induced failure of botulinum toxin therapy. Mov Disord. 2004 Mar;19 Suppl 8:S92-S100. doi: 10.1002/mds.20022.
67. Mejia NI, Vuong KD, Jankovic J. Long-term botulinum toxin efficacy, safety, and immunogenicity. Mov Disord. 2005 May;20(5):592-597. doi: 10.1002/mds.20376.

(C2020 by the author(s); licensee Ochsner Journal, Ochsner Clinic Foundation, New Orleans, LA. This article is an open (i) access article distributed under the terms and conditions of the Creative Commons Attribution (CC BY) license (creativecommons.org/licenses/by/4.0/legalcode) that permits unrestricted use, distribution, and reproduction in any medium, provided the original author(s) and source are credited. 